\title{
Anaemia in diabetes: is there a rationale to TREAT?
}

Received: 21 August 2005 / Accepted: 20 December 2005 / Published online: 4 April 2006

C) Springer-Verlag 2006

\begin{abstract}
Background: Anaemia is a common finding in patients with diabetes, particularly in those with overt nephropathy or renal impairment. In tertiary clinics, at least one outpatient in five with diabetes has anaemia, for whom it constitutes a significant additional burden. Discussion: Anaemia is associated with an increased risk of diabetic complications including nephropathy, retinopathy and macrovascular disease. Anaemia may also be significant in determining the outcome of heart failure and hypoxia-induced organ damage in diabetes. While several factors contribute to the increased prevalence of anaemia in diabetes, the failure of the kidney to increase erythropoietin in response to falling haemoglobin appears to be the dominant factor. Although there is a clear rationale for correcting anaemia in people with diabetes, it remains to be established whether this will lead to improved outcomes. Moreover, the balance of risks, costs, and benefits remains to be established in patients with diabetes. The Trial to Reduce Cardiovascular Events with Aranesp (darbepoetin alpha) Therapy (TREAT) is a randomised controlled trial designed to determine the impact of anaemia correction on mortality and non-fatal cardiovascular events in patients with type 2 diabetes and stage 3-4 nephropathy. Conclusion: It is anticipated that TREAT will help to define the optimal approach to the management of anaemia in diabetes.
\end{abstract}

Keywords Anaemia - Diabetes - Diabetic nephropathy · Haemoglobin · Microvascular disease

\footnotetext{
M. C. Thomas $(\bowtie) \cdot$ M. E. Cooper

Danielle Alberti Memorial Centre for Diabetes Complications, Baker Medical Research Institute,

Melbourne, VIC, Australia

e-mail: mthomas@baker.edu.au

Tel.: +61-3-85321280

Fax: $+61-3-85321480$

K. Rossing $\cdot$ H. H. Parving

Department of Physiology, Steno Diabetes Center,

Gentofte, Denmark
}

Abbreviations CKD: chronic kidney disease - ESRD: end stage renal disease $\cdot \mathrm{Hb}$ : haemoglobin $\cdot$ TREAT: Trial to Reduce Cardiovascular Events with Aranesp Therapy

\section{Background}

Anaemia is a common finding in chronic kidney disease (CKD), affecting over half of all patients [1]. Diabetes, as the most common single cause of CKD in the Western world, is therefore also the most common cause of renal anaemia. However, anaemia is also more common in diabetic nephropathy than in other renal diseases. For example, the Third National Health and Nutrition Examination Survey found that people in the general population with diabetes were nearly twice as likely to have anaemia as people without diabetes but with a similar degree of renal impairment [2]. Anaemia also develops earlier and is more severe in patients with diabetes than in patients with renal impairment from other causes [3, 4].

Anaemia can adversely affect the health of patients with diabetes. It may have a major impact on their sense of wellbeing, as well as impairing their ability to work and affecting their social and sexual lives. Anaemia is known to contribute significantly to morbidity, causing symptoms such as lack of energy, breathlessness, dizziness, poor appetite, reduced cognitive function and reduced exercise tolerance $[5,6]$. For patients with diabetes, many of whom already have an impaired quality of life, anaemia constitutes an unwelcome additional burden. A reduced haemoglobin $(\mathrm{Hb})$ level also identifies patients with diabetes at increased risk of adverse outcomes, independent of the presence or severity of nephropathy $[7,8]$. In addition, anaemia itself may contribute to the development and progression of micro- and macrovascular complications of diabetes.

Despite these facts, anaemia is unrecognised and largely untreated in patients with diabetes. This review will examine the factors leading to anaemia and its potential 
consequences in diabetes. In addition, we will explore the potential utility for anaemia correction.

\section{How common is anaemia in diabetes?}

Although anaemia is a common complication of diabetes, its true prevalence depends on what criteria are used to define it and the precise population in which these criteria are employed. For example, our previous studies indicated that $7-8 \%$ of ambulatory patients with diabetes in tertiary clinics have a $\mathrm{Hb}$ less than $110 \mathrm{~g} / 1$ [9-11] (Fig. 1). By contrast, the WHO guidelines, which are sex-specific, recommend investigation of anaemia when the $\mathrm{Hb}$ is less than $120 \mathrm{~g} / 1$ in women and less than $130 \mathrm{~g} / \mathrm{l}$ in men [12]. Using this definition, nearly 1 in $4(23 \%)$ patients with type 1 or type 2 diabetes had anaemia warranting evaluation [9-11]. More recently, the European Best Practice Guidelines for the Management of Anaemia in Patients with Chronic Renal Failure have defined anaemia as existing when the $\mathrm{Hb}$ falls more than two standard deviations below the mean for the general population, adjusted for age and sex (i.e. $<115 \mathrm{~g} / \mathrm{l}$ in adult female patients, $<135 \mathrm{~g} / \mathrm{l}$ in adult male patients aged less than $70,<120 \mathrm{~g} / 1$ in adult male patients aged over 70 years) [13]. Using this definition, approximately $21 \%$ of diabetic patients in our clinics have anaemia. It should be added that any definition of anaemia is arbitrary and that the risk associated with declining $\mathrm{Hb}$ levels has been shown to be continuous, even across the normal $\mathrm{Hb}$ range [7]. In this respect, anaemia performs in a similar manner to albuminuria, with arbitrary stages serving to stratify the associated risk.

\section{Which patients will have anaemia?}

The patients with diabetes who are at greatest risk of anaemia are readily identified by the presence of diabetic renal disease, manifested as impaired renal function and/or elevated albuminuria [9]. For example, in our population, $60 \%$ of patients with WHO-defined anaemia had a
GFR $<60 \mathrm{ml} \mathrm{min}^{-1} 1.73 \mathrm{~m}^{-2}$. As renal function fell, the prevalence of anaemia increased exponentially in both men and women (Fig. 2). Notably, the association between GFR and $\mathrm{Hb}$ was not confined to patients with elevated serum creatinine levels. Even in patients with a serum creatinine value within the normal laboratory range $(<110 \mu \mathrm{mol} / \mathrm{l})$, GFR was significantly associated with $\mathrm{Hb}[9,10]$. This finding emphasises the importance of estimated GFR in the management of patients with diabetes. This becomes even more important among elderly and sick individuals, in whom reduced muscle mass can lead to 'pseudonormalisation' of serum creatinine levels.

An increased prevalence of anaemia is also seen in diabetic patients without renal impairment (GFR> $90 \mathrm{ml} \mathrm{min}^{-1} 1.73 \mathrm{~m}^{-2}$ ) [9-11]. However, this does not mean that these patients do not have diabetic renal disease. Anaemia is also independently associated with albuminuria (Fig. 2), an early marker of microvascular inflammation and damage [14], which, like anaemia [3], precedes declining renal function associated with late-stage nephropathy. Recently, it has also been shown that, even in the absence of albuminuria, anaemia in patients with diabetes is largely the result of impaired renal functioning [15]. These strong links between the kidney and anaemia in diabetes probably reflect the unique vulnerability of the renal microcirculation to damage in diabetes [16]. Moreover, it is likely that significant damage is present before albumin is found in the urine [17]. Nonetheless, in a tertiary clinic setting, most patients with diabetes and anaemia can be identified by examining patients with moderate to severe renal impairment $\left(\mathrm{GFR}<60 \mathrm{ml} \mathrm{m^{-1 }} 1.73 \mathrm{~m}^{-2}\right)$ and/ or elevated albuminuria $(>20 \mu \mathrm{g} / \mathrm{min})$.

\section{The role of erythropoietin deficiency in diabetes- associated anaemia}

Several mechanisms potentially contribute to the preferential development of anaemia in patients with diabetes (Table 1). One major factor in the genesis of anaemia is the failure to increase circulating erythropoietin concentrations
Fig. 1 The distribution of haemoglobin levels in ambulatory patients with type 2 diabetes in Australian diabetes clinics $(n=2258)$

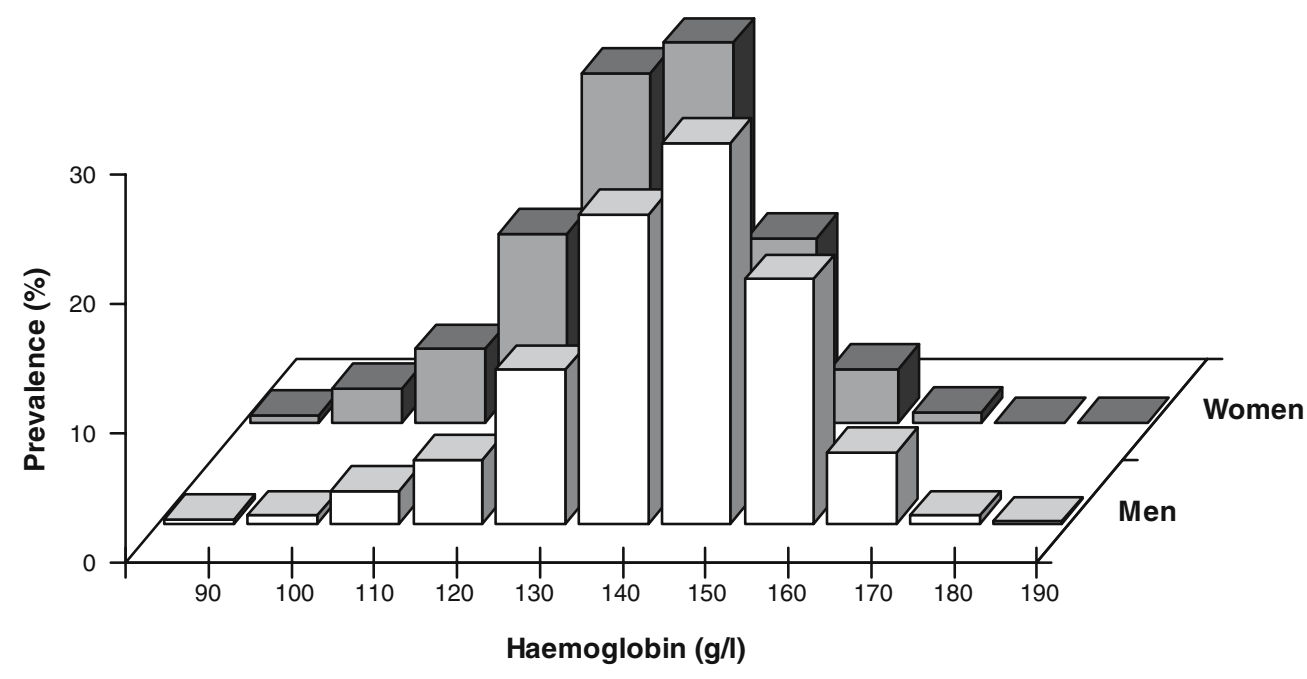


Fig. 2 The prevalence of WHO-defined anaemia, stratified according to level of creatinine clearance and level of albuminuria, in ambulatory patients with type 2 diabetes in Australian diabetes clinics $(n=2258)$. AER, albumin excretion rate

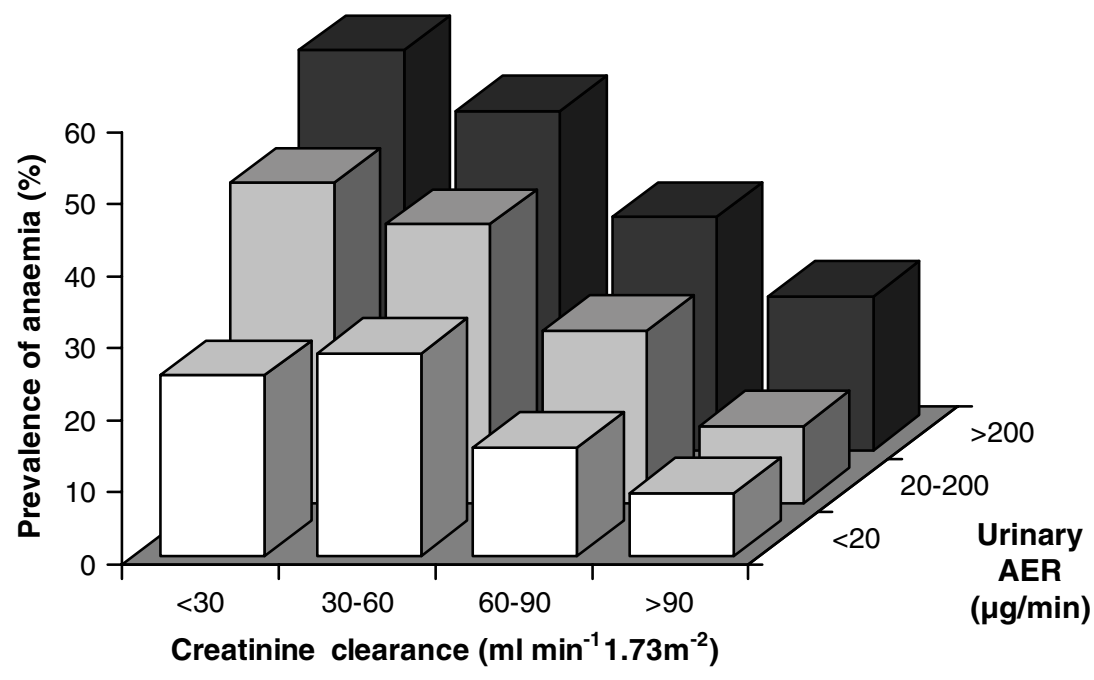

in response to falling $\mathrm{Hb}$ (so-called functional erythropoietin deficiency) $[4,15,18,19]$. In healthy individuals, any decrease in $\mathrm{Hb}$ is normally matched by an exponential increase in renal erythropoietin production. In non-renal forms of anaemia (e.g. iron deficiency, haemolysis), erythropoietin production reaches high levels to induce compensatory erythropoiesis. However, after excluding other identifiable causes of anaemia (in particular, iron deficiency) most (>95\%) have erythropoietin levels that are inappropriately within the normal range, denoting functional erythropoietin deficiency (Fig. 3) [20]. Although most of these patients have moderate renal impairment and/ or albuminuria (i.e. overt renal damage) even in the absence of signs of renal disease, functional erythropoietin deficiency appears to be a major contributor [15].

While these findings confirm the failure of the kidney to produce erythropoietin in response to falling $\mathrm{Hb}$ as a key component of anaemia in patients with diabetes, that is not to say that other (non-renal) factors do not contribute. On the contrary, patients with diabetes have several metabolic and functional abnormalities of their red blood cells, including reduced erythrocyte survival [21]. Diabetes is also associated with systemic inflammation, occult blood loss and haematinic deficiencies [16]. Indeed, one-third of

Table 1 Possible factors contributing to anaemia in patients with diabetes

Reduced renal production of Other contributors erythropoietin

Microvascular damage

Chronic hypoxia

Oxidative stress

Local inflammation

Autonomic neuropathy

Increased salt reabsorption

Hyperfiltration

Urinary erythropoietin loss patients with functional erythropoietin deficiency in our surveys also have reduced iron availability. Thus, in the setting of impaired renal compensation, it is conceivable that even minor changes in red cell turnover or iron availability may contribute to a progressive fall in $\mathrm{Hb}$ and ultimately anaemia. As a result, the standard thresholds used to denote absolute iron deficiency may be inappropriately low for patients with diabetic kidney disease. The same phenomenon can be observed in patients on haemodialysis, who may still be responsive to iron supplementation despite relatively normal iron indices (functional iron deficiency).

\section{Why does the diabetic kidney not generate adequate erythropoietin in response to anaemia?}

The precise mechanisms by which diabetes impairs the renal erythropoietin response to reduced $\mathrm{Hb}$ remain to be established. While functional erythropoietin deficiency is clearly linked to renal dysfunction in diabetes, the reduction in synthesis of erythropoietin in response to anaemia appears to be beyond that seen in other renal (and particularly glomerular) diseases [22]. A number of mechanisms potentially contribute to the preferential development of anaemia in patients with diabetes. For example, the predominance of damage to specific cells and to the vascular architecture of the renal tubulointerstitium, and the resulting systemic inflammation, autonomic neuropathy, and induction of inhibitors of erythropoietin release, have all been suggested as contributors to impaired renal erythropoietin production and release.

Like anaemia, tubulointerstitial damage can be seen in diabetes, independent of and in advance of later changes, such as declining GFR. For example, thickening and reduplication of the tubular and epithelial basement membrane can be readily observed in the early diabetic kidney, even among normoalbuminuric patients [17]. It is conceivable that damage to the erythropoietin-producing cells in the cortical interstitium or disruption of the delicate interaction between tubule, peritubular fibroblast and 
Fig. 3 The relationship between haemoglobin $(\mathrm{Hb})$ levels and erythropoietin levels in patients with type 2 diabetes and adequate iron availability (transferrin saturation $>16 \%$ ) Black symbols, patients with WHO-defined anaemia; dotted line, 2 standard deviations above the mean erythropoietin level for patients with $\mathrm{Hb}$ in the normal range and normal renal function

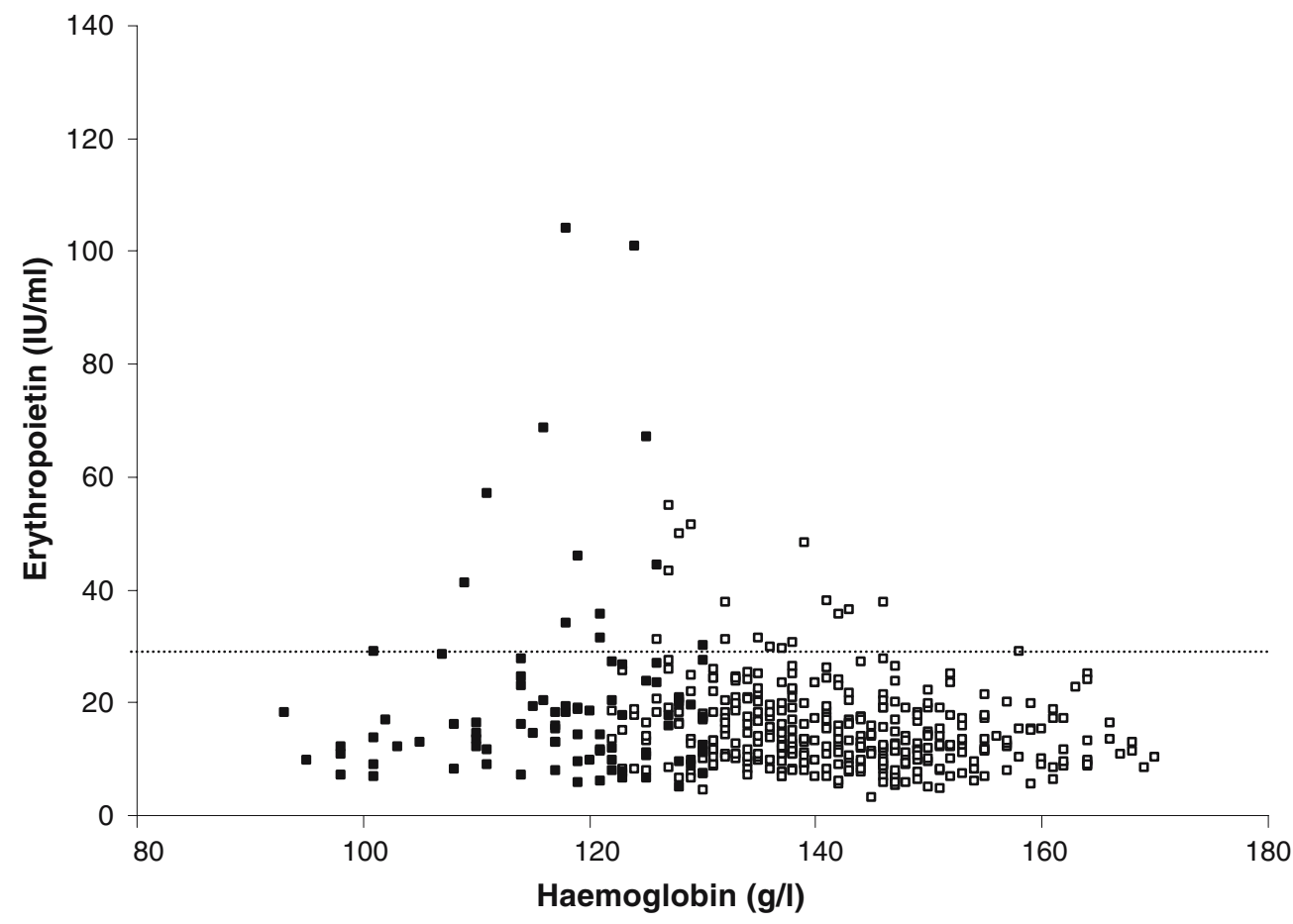

endothelium that is required for normal haematopoietic function in the kidney may contribute to impaired erythropoietin release. In fact, endogenous erythropoietin production has been suggested as a possible marker of the severity of tubulointerstitial damage in diabetes [19]. However, the fact that patients with diabetes and anaemia are able to mount an appropriate response to acute hypoxia [23], suggests that the cells which produce erythropoietin are not simply lost in diabetes. Rather that the 'tissue oxygenationerythropoietin - $\mathrm{Hb}$ ' feedback mechanism may operate at a lower set-point in the diabetic tubule and peritubular milieu.

\section{Does anaemia contribute to diabetic complications?}

Anaemia may contribute to both morbidity and mortality in diabetes in a number of ways. Certainly, untreated anaemia significantly contributes to the reduced quality of life seen in patients with $\mathrm{CKD}$, including impaired physical performance, cognitive function, sleep, appetite, sexual function, social activities, and employment. For example, in a recent survey, over half of all patients with diabetes experienced tiredness to some extent and this proportion increased to $74 \%$ in those with anaemia [24]. Furthermore, fatigue was associated with significant functional morbidity, reduced independence and a poorer quality of life.

Anaemia is associated with an increased risk of the vascular complications of diabetes including nephropathy $[7,25,26]$, retinopathy $[27,28]$, neuropathy [3], impaired wound healing [29] and macrovascular disease. A reduced $\mathrm{Hb}$, even within the normal range, identifies patients with type 2 diabetes who are at increased risk of progressive renal disease, hospitalisation and premature death [7]. It is important to note that anaemia per se does not cause microvascular injury (e.g. chronic iron deficiency does not lead to end-stage renal disease [ESRD]). Moreover, because anaemia may be considered a manifestation of microvascular disease [16], it is easy to understand why patients with anaemia, as a surrogate marker for comorbidity, may appear more prone to microvascular complications. However, there is some evidence to suggest that anaemia may also modulate the activity of pathways that lead to progressive end-organ damage in diabetes.

Tissue hypoxia is known to have a key role in diabetesassociated organ damage, associated with a range of mitogenic and fibrogenic effects implicated in the progression of microvascular disease. For example, hypoxia modifies the expression of genes involved in angiogenesis and capillary permeability, vasomotor response, glycolysis, matrix metabolism and cell survival [30]. Anaemia may also have important haemodynamic effects in diabetic tissues. For example, anaemia independently results in elevated sympathetic activity, activation of the intra-renal renin-angiotensin system and release of antidiuretic hormone [31], all pathways that are implicated in the development of proteinuria [30] and hypertension in CKD [32].

In the heart, chronic anaemia results in increased cardiac output, volume overload, increased heart rate and, ultimately, progressive left ventricular hypertrophy and diastolic dysfunction. In addition, an increase in myocardial hypoxia associated with anaemia may be particularly important in patients with diabetes, because many also have established cardiovascular disease or impaired cardiac function. In particular, the kind of diabetic patients that will have anaemia (those with overt nephropathy, renal impairment, prolonged duration of disease. etc.) are 
precisely the patients that have cardiac disease. For example, we have recently shown that $94 \%$ of unselected diabetic patients with anaemia have abnormal cardiac function that is detectable on transthoracic echocardiography, associated with increased left ventricular mass and impaired relaxation indices [33]. It is now clear that anaemia is a potent adverse risk factor for new-onset heart failure [34], as well as a marker for poor outcomes in patients with established cardiac dysfunction [35]. Anaemia may be operating in the same way in patients with diabetes (given that most diabetic patients with anaemia have cardiac dysfunction). Moreover, the increased prevalence of anaemia in patients with diabetes may contribute to the worse prognosis of heart failure in patients with diabetes compared to non-diabetic patients [36].

Overall, anaemia appears to multiply the risk of significant morbidity and mortality. If you have heart failure, renal disease, or both, the additional burden of anaemia significantly increases your risk of adverse outcomes [37]. Importantly, this risk appears to be regardless of aetiology of anaemia and whether or not erythropoietin levels are elevated or in the normal range [20]. In addition, the impact of reduced $\mathrm{Hb}$ in diabetes is not confined to patients with anaemia. For example, in the RENAAL study, reduced $\mathrm{Hb}$, even within the range considered 'normal' was associated with an increased risk of ESRD or death [7]. Similarly, in a prospective study of patients with diabetes and persistent macroalbuminuria, baseline $\mathrm{Hb}$, even within the normal range, predicted time to doubling of serum creatinine or ESRD independently of other risk factors including baseline GFR (Fig. 4) [8].

\section{What evidence is there for correcting anaemia?}

At present, there is no conclusive evidence that correcting anaemia significantly improves clinical outcomes in patients with CKD, apart from quality-of-life indices [38]. Nonetheless, from the perspective of a patient with diabetic nephropathy (and therefore risk of heart failure, CHD, retinopathy, etc.), an intervention that reproducibly improves ability to work, exercise tolerance, and cognitive and sexual function is not insignificant. Consequently, current international guidelines allow the use of erythropoietin in patients with CKD and anaemia when other causes have been excluded [13]. However, many countries limit the use of erythropoietin to patients with severe renal impairment or ESRD. Such a practice is clearly problematic because the likelihood of functional erythropoietin deficiency as a contributor to anaemia in patients with diabetes is not dependent on the severity of renal impairment. In addition, most patients with diabetes do not survive long enough to develop severe renal impairment nor to develop anaemia severe enough to qualify for therapy under the current guidelines. Furthermore, some data suggest that early correction of anaemia may be more beneficial than late interventions, where complications are advanced and irreversible. For example, while correction of anaemia in patients with advanced kidney disease may stabilise left ventricular hypertrophy [38], earlier intervention may lead to regression [39].

There is limited evidence to suggest that correction of anaemia, specifically in patients with complications of diabetes, might be beneficial. For example, a few small studies have demonstrated that correction of anaemia is associated with a reduction in retinal exudates [40] and macular oedema [41]. Treatment with erythropoietin in diabetic patients with heart failure may also reduce the length of hospitalisation and improve New York Heart Association functional class [42]. In experimental models of diabetes, treatment with erythropoietin has been shown to protect against the development of diabetic neuropathy as well as to reverse established disease [43]. However, it remains to be established whether these actions are the
Fig. 4 In patients with type 2 diabetes and overt nephropathy, the haemoglobin level is associated with a shorter time to doubling of serum creatinine or ESRD, after adjusting for baseline systolic blood pressure, albuminuria and glycaemic control (adapted from [8]); $* * p<0.01$ vs patients with $\mathrm{Hb} 140-160$

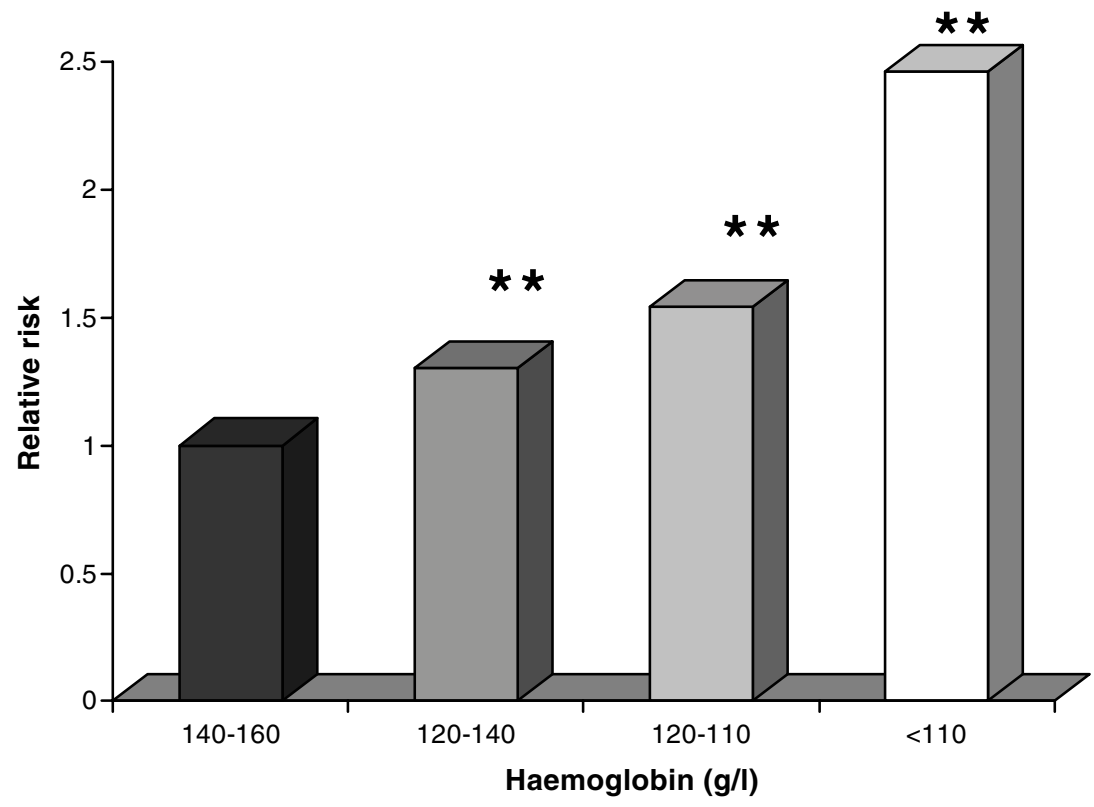


result of correction of the anaemia, or of the pleiotropic actions of erythropoietin on the physiological response to hypoxia and oxidative stress [44].

\section{A rationale to TREAT}

Given that anaemia associated with functional erythropoietin deficiency is common in patients with diabetes, there is a clear rationale for the use of erythropoietin or related analogues in diabetic patients. However, while correction of anaemia improves quality of life and exercise tolerance, the impact of anaemia correction on hard clinical outcomes in patients with diabetes remains to be established. Moreover, there is a clear potential for deleterious effects from erythropoietin, such as raised blood pressure, increased blood viscosity and elevated peripheral vascular resistance, which may have negative impacts on patients with diabetes. Erythropoietin is also a potentially costly addition to an already stretched pharmaceutical budget. Consequently, the true balance of risks and benefits can only be answered by large randomised controlled studies.

TREAT is an international, multicentre, double-blind randomised controlled trial designed to test the hypothesis that correction of anaemia (as defined by $\mathrm{Hb} \leq 110 \mathrm{~g} / \mathrm{l}$ ) with the erythropoietin analogue, darbepoetin alpha, to a target $\mathrm{Hb}$ of $130 \mathrm{~g} / \mathrm{l}$ in patients with CKD and type 2 diabetes mellitus will reduce the risk of a composite primary end point of death or cardiovascular morbidity, including myocardial infarction, acute myocardial ischaemia, congestive heart failure, and stroke. Eligible TREAT subjects should have type 2 diabetes mellitus and CKD, defined by an estimated GFR of $20-60 \mathrm{ml} \mathrm{min}^{-1} 1.73 \mathrm{~m}^{-2}$. Consequently, most patients will have moderate renal impairment, rather than the severe or pre-ESRD studied in previous and current trials (e.g. CREATE [45], CHOIR [46]). As most patients with diabetic nephropathy do not survive long enough to develop ESRD, targeted intervention in these patients would seem to be more logical than delayed intervention in selected survivors with advanced disease.

TREAT is an event-driven trial and is currently enrolling approximately 4,000 eligible subjects over 2 years. It is expected that the majority of subjects will be recruited in North America, Western Europe, Australia and Latin America. This sample size should yield approximately 1,203 composite primary events over a total of approximately 4.5 years of study, providing $80 \%$ power to detect a treatment effect of $20 \%$. Enrolled subjects will be randomised either to receive darbepoetin alpha to achieve and maintain target $\mathrm{Hb}$ of $130 \mathrm{~g} / \mathrm{l}$ or to the control arm, where they will receive placebo for $\mathrm{Hb} \geq 90 \mathrm{~g} / \mathrm{l}$ and rescue therapy with darbepoetin alpha for $\mathrm{Hb}<90 \mathrm{~g} / \mathrm{l}$ until $\mathrm{Hb}$ is again $\geq 90 \mathrm{~g} / \mathrm{l}$, when placebo will resume.

Justification for the threshold $\mathrm{Hb}$ level for rescue of $90 \mathrm{~g} / \mathrm{l}$ is based on clinical and statistical considerations. First, it is designed to protect patient safety by minimising symptomatic anaemia. The guidelines of the National Kidney
Foundation for anaemia management in CKD indicate that quality of life is either not influenced or is influenced only slightly when $\mathrm{Hb}$ increases from 80 to $90-100 \mathrm{~g} / \mathrm{l}$, and reviews of clinical trials by the Cochrane Collaboration indicate that there is no increased safety risk at an $\mathrm{Hb}$ of $90 \mathrm{~g} / \mathrm{l}$ as compared with higher $\mathrm{Hb}$ [38]. Moreover, there are currently no convincing trial data to support the correction of anaemia in these patients. Consistent with previous studies in CKD [47], it is expected that less than $10 \%$ of subjects in the placebo arm will experience an $\mathrm{Hb}<90 \mathrm{~g} / \mathrm{l}$ and therefore require rescue therapy with darbepoetin alpha. Lastly, statistical modelling suggests a feasible sample size with the threshold for $\mathrm{Hb}$ rescue set at $90 \mathrm{~g} / \mathrm{l}$.

\section{Concluding remarks}

In summary, anaemia is a common finding in diabetes, particularly in patients with overt nephropathy or renal impairment. In tertiary clinics at least one outpatient in five with type 1 or type 2 diabetes has anaemia [10, 11], to whom it constitutes a significant additional burden. Anaemia is associated with an increased risk of diabetic complications including nephropathy, retinopathy and neuropathy. Anaemia may also be significant in determining the outcome of heart failure and hypoxia-induced organ damage associated with macrovascular disease in diabetes. Although there is a clear rationale to correct functional erythropoietin deficiency in patients with diabetes, there is currently no trial evidence for this practice. Moreover, the balance of risks, costs and benefits remains to be established in patients with diabetes. TREAT is designed to provide the critical and unbiased risk/benefit information that is needed to guide medical practice in this high-risk population, and will help define the optimal approach to the management of anaemia in diabetes. In the meantime, the detection of anaemia should be used to identify patients with diabetes who are at increased risk of adverse clinical outcomes. Optimal metabolic and blood pressure control remain the best way to prevent anaemia by preventing microvascular damage at the outset.

\section{References}

1. McClellan W, Aronoff SL, Bolton WK et al (2004) The prevalence of anemia in patients with chronic kidney disease. Curr Med Res Opin 20:1501-1510

2. Astor BC, Muntner P, Levin A et al (2002) Association of kidney function with anemia: the Third National Health and Nutrition Examination Survey (1988-1994). Arch Intern Med 162:1401-1408

3. Bosman DR, Winkler AS, Marsden JT et al (2001) Anemia with erythropoietin deficiency occurs early in diabetic nephropathy. Diabetes Care 24:495-499

4. Ishimura E, Nishizawa Y, Okuno S et al (1998) Diabetes mellitus increases the severity of anemia in non-dialyzed patients with renal failure. J Nephrol 11:83-86

5. Lundin AP (1989) Quality of life: subjective and objective improvements with recombinant human erythropoietin therapy. Semin Nephrol 9:22-29 
6. No authors listed (1990) Association between recombinant human erythropoietin and quality of life and exercise capacity of patients receiving haemodialysis. Canadian Erythropoietin Study Group. BMJ 300:573-578

7. Keane WF, Lyle PA (2003) Recent advances in management of type 2 diabetes and nephropathy: lessons from the RENAAL study. Am J Kidney Dis 41:S22-S25

8. Rossing K, Christensen PK, Hovind P et al (2004) Progression of nephropathy in type 2 diabetic patients. Kidney Int 66:1596-1605

9. Thomas MC, MacIsaac RJ, Tsalamandris C et al (2003) Unrecognized anemia in patients with diabetes: a crosssectional survey. Diabetes Care 26:1164-1169

10. Thomas MC, MacIsaac RJ, Tsalamandris C et al (2004) The burden of anaemia in type 2 diabetes and the role of nephropathy: a cross-sectional audit. Nephrol Dial Transplant 19:1792-1797

11. Thomas MC, MacIsaac RJ, Tsalamandris C et al (2004) Anemia in patients with type 1 diabetes. J Clin Endocrinol Metab 89:4359-4363

12. World Health Organization (1968) Nutritional Anemias: Report of a WHO Scientific Group. WHO, Geneva

13. Locatelli F, Aljama P, Barany P et al (2004) Revised European best practice guidelines for the management of anaemia in patients with chronic renal failure. Nephrol Dial Transplant 19 (Suppl 2):ii1-ii47

14. Deckert T, Feldt-Rasmussen B, Borch-Johnsen K et al (1989) Albuminuria reflects widespread vascular damage. The Steno hypothesis. Diabetologia 32:219-226

15. Craig KJ, Williams JD, Riley SG et al (2005) Anemia and diabetes in the absence of nephropathy. Diabetes Care 28:1118-1123

16. Thomas MC, Tsalamandris C, MacIssaac R, Jerums G (2005) Anemia in diabetes; an emerging complication of microvascular disease. Current Diabetes Reviews 1:107-126

17. Brito PL, Fioretto P, Drummond K et al (1998) Proximal tubular basement membrane width in insulin-dependent diabetes mellitus. Kidney Int 53:754-761

18. Winkler AS, Marsden J, Chaudhuri KR et al (1999) Erythropoietin depletion and anaemia in diabetes mellitus. Diabet Med $16: 813-819$

19. Inomata S, Itoh M, Imai H, Sato T (1997) Serum levels of erythropoietin as a novel marker reflecting the severity of diabetic nephropathy. Nephron 75:426-430

20. Thomas MC, Cooper ME, Tsalamandris C et al (2005) Anemia with impaired erythropoietin response in diabetic patients. Arch Intern Med 165:466-469

21. Jones RL, Peterson CM (1981) Hematologic alterations in diabetes mellitus. Am J Med 70:339-352

22. de Klerk G, Wilmink JM, Rosengarten PC et al (1982) Serum erythropoietin (ESF) titers in anemia of chronic renal failure. $\mathrm{J}$ Lab Clin Med 100:720-734

23. Bosman DR, Osborne CA, Marsden JT et al (2002) Erythropoietin response to hypoxia in patients with diabetic autonomic neuropathy and non-diabetic chronic renal failure. Diabet Med 19:65-69

24. Stevens PE, O'Donoghue DJ, Lameire NR (2003) Anaemia in patients with diabetes: unrecognised, undetected and untreated? Curr Med Res Opin 19:395-401

25. Ueda H, Ishimura E, Shoji $T$ et al (2003) Factors affecting progression of renal failure in patients with type 2 diabetes. Diabetes Care 26:1530-1534

26. Yokoyama H, Tomonaga O, Hirayama M et al (1997) Predictors of the progression of diabetic nephropathy and the beneficial effect of angiotensin-converting enzyme inhibitors in NIDDM patients. Diabetologia 40:405-411

27. Davis MD, Fisher MR, Gangnon RE et al (1998) Risk factors for high-risk proliferative diabetic retinopathy and severe visual loss: Early Treatment Diabetic Retinopathy Study Report \#18. Invest Ophthalmol Vis Sci 39:233-252
28. Qiao Q, Keinanen-Kiukaanniemi S, Laara E (1997) The relationship between hemoglobin levels and diabetic retinopathy. J Clin Epidemiol 50:153-158

29. Roman RM, Lobo PI, Taylor RP et al (2004) Prospective study of the immune effects of normalizing the hemoglobin concentration in hemodialysis patients who receive recombinant human erythropoietin. J Am Soc Nephrol 15:1339-1346

30. Deicher R, Horl WH (2003) Anaemia as a risk factor for the progression of chronic kidney disease. Curr Opin Nephrol Hypertens 12:139-143

31. Fine LG, Bandyopadhay D, Norman JT (2000) Is there a common mechanism for the progression of different types of renal diseases other than proteinuria? Towards the unifying theme of chronic hypoxia. Kidney Int Suppl 75:S22-S26

32. Strojek K, Grzeszczak W, Gorska J et al (2001) Lowering of microalbuminuria in diabetic patients by a sympathicoplegic agent: novel approach to prevent progression of diabetic nephropathy? J Am Soc Nephrol 12:602-605

33. Srivastava PM, Thomas MC, Calafiore P et al (2006) Diastolic dysfunction is associated with anaemia in patients with Type II diabetes. Clin Sci (Lond) 110:109-116

34. Sandgren PE, Murray AM, Herzog CA et al (2005) Anemia and new-onset congestive heart failure in the general Medicare population. J Card Fail 11:99-105

35. Wexler D, Silverberg D, Blum M et al (2005) Anaemia as a contributor to morbidity and mortality in congestive heart failure. Nephrol Dial Transplant 20(Suppl 7):vii11-vii15

36. Dries DL, Sweitzer NK, Drazner MH et al (2001) Prognostic impact of diabetes mellitus in patients with heart failure according to the etiology of left ventricular systolic dysfunction. J Am Coll Cardiol 38:421-428

37. Collins AJ (2003) The hemoglobin link to adverse outcomes. Adv Stud Med 3:S14-S17

38. Cody J, Daly C, Campbell M et al (2001) Recombinant human erythropoietin for chronic renal failure anaemia in pre-dialysis patients. Cochrane Database Syst Rev CD003266

39. Hayashi T, Suzuki A, Shoji T et al (2000) Cardiovascular effect of normalizing the hematocrit level during erythropoietin therapy in predialysis patients with chronic renal failure. Am J Kidney Dis 35:250-256

40. Friedman EA, L'Esperance FA, Brown CD, Berman DH (2003) Treating azotemia-induced anemia with erythropoietin improves diabetic eye disease. Kidney Int (Suppl):S57-S63

41. Friedman EA, Brown CD, Berman DH (1995) Erythropoietin in diabetic macular edema and renal insufficiency. Am J Kidney Dis 26:202-208

42. Silverberg DS, Wexler D, Blum M et al (2003) The effect of correction of anaemia in diabetics and non-diabetics with severe resistant congestive heart failure and chronic renal failure by subcutaneous erythropoietin and intravenous iron. Nephrol Dial Transplant 18:141-146

43. Bianchi R, Buyukakilli B, Brines M et al (2004) Erythropoietin both protects from and reverses experimental diabetic neuropathy. Proc Natl Acad Sci USA 101:823-828

44. Chatterjee PK (2005) Pleiotropic renal actions of erythropoietin. Lancet 365:1890-1892

45. Macdougall IC, Steering Committee of the CREATE trial, CREATE Study Group (2003) CREATE: new strategies for early anaemia management in renal insufficiency. Nephrol Dial Transplant 18(Suppl 2):ii13-ii16

46. http://www.hden.com/symp/02rpasat/talks/red.htm (accessed 15 November 2005)

47. Gouva C, Nikolopoulos P, Ioannidis JP, Siamopoulos KC (2004) Treating anemia early in renal failure patients slows the decline of renal function: a randomized controlled trial. Kidney Int 66:753-760 